Br. J. Surg. 1992, Vol. 79, June. 525-528

\section{Effect of antibiotics in fibrin sealant on healing colonic anastomoses in the rat}

\author{
A. C. van der Ham, \\ W. J. Kort, I. M. Weijma, \\ H. F. G. M. van den Ingh* \\ and $H$. Jeekel \\ Laboratory for Experimental \\ Surgery, Erasmus University and \\ * Department of Pathology. \\ St Clara Ziekenhuis, Rotterdam, \\ The Netherlands \\ Correspondence to: \\ Dr A. C. van der Ham, Laboratory \\ for Experimental Surgery, \\ Dr. Molewaterplein 50, PO Box \\ 1738, 3000 DR Rotterdam, \\ The Netherlands
}

\begin{abstract}
In 90 rats a colonic anastomosis was constructed with 12 interrupted 7/0 polypropylene sutures. Group $1(\mathrm{n}=30)$ served as a control group. In group $2(\mathrm{n}=30)$ the anastomosis was sealed with fibrin adhesive and in group $3(\mathrm{n}=30)$ a mixture of fibrin, clindamycin and cefotaxime was used. On days 2, 4 and 7, ten animals in each group were killed. Adhesion formation was significantly increased in groups 2 and 3 compared with the control group. On day 2 the anastomosis was significantly stronger after sealing with antibiotic-fibrin mixture. On day 4 the bursting pressure in group 2 was significantly lower than in groups 1 and 3. At the same time the concentration of hydroxyproline was significantly reduced in group 2 , but not in group 3 . The addition of antibiotics prevents the negative effect of fibrin adhesive on the healing colonic anastomosis and contributes to a stronger anastomosis on day 2 after operation.
\end{abstract}

Leakage from colonic and rectal anastomoses has a reported incidence of up to 50 per cent ${ }^{1}$ and is associated with significantly increased mortality and morbidity rates ${ }^{2}$. Fibrin sealant is a multicomponent biological adhesive made from concentrated human fibrinogen which can be used to establish haemostasis or as an adhesive in wound repair. Additional sealing with fibrin sealant has been advocated in normal and high-risk colonic anastomosis to prevent anastomotic leakage ${ }^{3-7}$. Experimental studies provide conflicting results and prospective, randomized clinical studies are lacking ${ }^{8.9}$. A negative influence of additional fibrin sealant on the healing colonic anastomosis has recently been demonstrated in the rat $^{10}$. This negative effect might be caused by an increased inflammatory reaction near the anastomosis ${ }^{9,10}$.

The quantity and quality of collagen in the submucosal layer of the intestinal wall determines the strength of the healing intestine ${ }^{11}$. After colonic anastomosis there is first a period of breakdown of collagen, followed by synthesis ${ }^{12-14}$. Collagen is highly resistant to proteolytic agents but is readily degraded by collagenase. Factors directly influencing the activity of collagenase are infection and inflammation around infected anastomoses ${ }^{15,16}$. Bacteria and inflammatory cells are known to produce collagenase ${ }^{17,18}$. As every colonic anastomosis must be considered to be contaminated by intestinal bacteria, the fibrin clot will be infected too. It is possible to mix antibiotics with fibrin glue without impairment of its adhesive and clotting properties. High local antibiotic concentrations are then slowly released from the fibrin $\operatorname{clot}^{19}$.

This study was designed to determine whether the addition of antibiotics abolishes the negative effect of fibrin sealing on the strength and collagen metabolism of healing colonic anastomoses in the rat.

\section{Materials and methods}

Ninety male Wag/Rij rats, weighing $180-230 \mathrm{~g}$, were randomly ailocated to three treatment groups and were allowed water (acidified, $\mathrm{pH} \mathrm{3.0)} \mathrm{and} \mathrm{food} \mathrm{(AM} \mathrm{II;} \mathrm{Hope} \mathrm{Farms,} \mathrm{Woerden,} \mathrm{The} \mathrm{Netherlands)}$ ad libitum before and after operation. Using ether anaesthesia and through a midline incision, $1 \mathrm{~cm}$ of the left colon, $3 \mathrm{~cm}$ proximal to the peritoneal reflection, was resected. A single-layer end-to-end anastomosis was performed with 12 interrupted, inverting $7 / 0$ polypropylene (Prolene; Ethicon, Norderstedt, Germany) stitches in a standard fashion. The resected segment of colon was frozen and kept at $-80^{\circ} \mathrm{C}$ until analysis, to serve as an individual control. The experimental groups were: group 1, control sutured anastomosis; group
}

2, sutured anastomosis plus human fibrin sealant; group 3, sutured anastomosis plus fibrin-antibiotic complex. The human fibrin sealant (Tissucol; Immuno AG, Vienna, Austria) was prepared according to the manufacturer's instructions. The sealant consists of a freeze-dried protein concentration of human fibrinogen $(120 \mathrm{mg} / \mathrm{ml})$ which is reconstituted in a solution of aprotinin (3000 kallidinogenase inactivator units $/ \mathrm{ml})$ and a solution of thrombin ( 500 units $/ \mathrm{ml})$ and calcium chloride $(40 \mathrm{mmol} / 1)$. In treatment group $3,1 \mathrm{ml}$ thrombin solution was mixed with $50 \mathrm{mg}$ cefotaxime and $50 \mathrm{mg}$ clindamycin. After preheating to $37^{\circ} \mathrm{C}$ the components were reconstituted in their solutions and drawn up in separate syringes. On mixing and application the fibrinogen was activated to form fibrin and the solution was transformed into a rubber-like adhesive mass. The fibrin-antibiotic complex contains $25 \mathrm{mg}$ cefotaxime and $25 \mathrm{mg}$ clindamycin per $\mathrm{ml}$ fibrin glue. For one anastomosis $0.2 \mathrm{ml}$ fibrin sealant was used. On days 2,4 and 7 , ten rats from each group had the laparotomy incision reopened under ether anaesthesia and the degree of adhesion formation was assessed: 0 , no adhesions; $1+$, minimal adhesions, mainly between anastomosis and omentum; $2+$, moderate adhesions, i.e. between omentum and the anastomotic site and between the anastomosis and a loop of small bowel; $3+$, severe and extensive adhesions, including abscess formation ${ }^{9}$. The rectum was then cannulated and the left colon was ligated twice, $1 \mathrm{~cm}$ proximal and $1 \mathrm{~cm}$ distal to the anastomosis, the latter around the rectal cannula. Care was taken not to disrupt the anastomosis and its adhesions. The rectal cannula was connected to an infusion pump (Hospal; Dasco Spa, Medolla, Italy), with a side arm to a pressure transducer connected to a recorder. The in vivo anastomotic bursting pressure was measured by infusing normal saline at a constant rate of $1 \mathrm{ml} / \mathrm{min}$, and was marked by an abrupt loss of pressure. After measuring the bursting pressure the animal was killed. The left colon, including the anastomosis, was excised and dissected free of mesenteric fat. Three rings of colon tissue $0.5 \mathrm{~cm}$ wide were cut: one ring of tissue containing the anastomosis, one ring proximal and one ring distal to the anastomosis. For histological examination a small segment of the anastomotic ring was cut and placed in 4 per cent formaldehyde. The remaining tissue samples were immediately frozen and kept at $-80^{\circ} \mathrm{C}$ for hydroxyproline assay.

Hydroxyproline was determined using a modified version of the colorimetric assay of Stegeman et al 20,2

Collagen concentrations were calculated in micrograms per milligram dry weight. The collagen concentration of the control colon was used to calculate any change in collagen content.

Sections of 5- $\mu \mathrm{m}$ thickness were cut and stained with haematoxylin and eosin. A periodic acid-Schiff, a Gomori and a Weigert-van Gieson stain were used to assess the tissue reaction. The inflammatory infiltrate (neutrophils, eosinophils, macrophages) and tissue organization (fibroblast and capillary proliferation) were scored semiquantitatively as follows: + , numerous; \pm , occasionally present; - , absent.

For statistical analysis the mean values and the standard error of the mean (s.e.m.) were calculated. Results were compared using one-way analysis of variance (ANOVA) with the Student-Newman- 
Keuls test, $\chi^{2}$ test and Fisher's exact test where appropriate. The null hypothesis of no difference was rejected at a $P$ value of 0.05 .

\section{Results}

All rats survived and no animal showed macroscopic evidence of leakage from the anastomosis. There were no differences in change of body-weight.

The results of adhesion formation are presented in Table 1. Adhesion formation was more extensive in groups 2 and 3 compared with group 1 by day 4 . No animal showed abscess formation.

The results of anastomotic bursting pressure measurements are presented in Figure 1. On day 2 bursting invariably occurred at the anastomosis. On day 4, 80 per cent of bursting in the control group occurred at the anastomosis; in groups 2 and 3 rupture without exception took place at the suture line. On day 7 the rupture invariably occurred outside the anastomosis in groups 1 and 3 ; in one animal in group 2 the anastomosis was the place of rupture. Bursting was most likely to take place proximal to the anastomosis in 80,70 and 90 per cent of animals

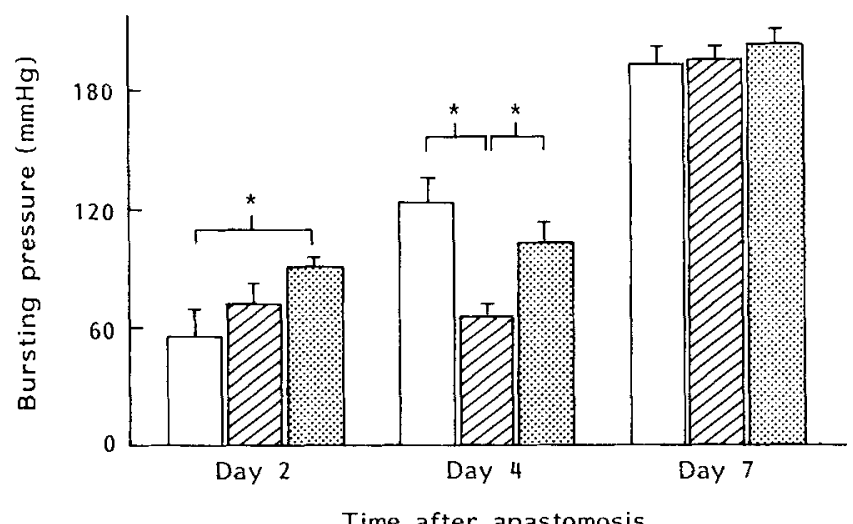

Figure 1 Colonic bursting pressure on days 2, 4 and 7 after creation of an end-to-end anastomosis. Values are mean(s.e.m.); $\mathrm{n}=10$.

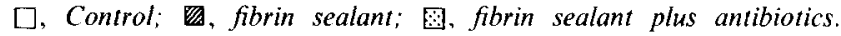
${ }^{*} \mathrm{P}<0.05$ ( ANOVA and Newman-Keuls test) in groups 1,2 and 3 , respectively. On day 7 the colon wall was significantly weaker proximal to the anastomosis compared with the distal colon $(P<0.01)$.

The values of collagen concentration around the anastomosis and relative change compared with individual normal values are presented in Table 2. Hydroxyproline concentration was lowest on day 2 in all groups. The relative loss of collagen was prominent in all groups on most occasions. Overall there were slight differences in relative collagen loss between groups 1 and 3 ; these changes became statistically significant only on day 7 . Figure 2 illustrates the relative change of collagen around the anastomosis.

Histological examination showed remnants of fibrin glue outside the anastomosis on days 2 and 4 (Figure 3); on day 7 , however, this fibrin was not demonstrated. On days 2 and 4 the fibrin sealant in groups 2 and 3 was heavily infiltrated and surrounded by neutrophilic granulocytes. On day 4 this neutrophilic infiltrate was more pronounced in group 2 than in group 3 (Figure 4). The intestinal wall showed an infiltration of neutrophilic and eosinophilic granulocytes and macrophages. Apart from the number of neutrophils, no clear differences could be found between the treatment groups.

On day 2 fibroblasts were present only occasionally. On days 4 and 7 macrophages and fibroblasts were abundant in all groups, while granulocytes had reduced in number again. No differences were noted concerning the number of fibroblasts and capillary proliferation.

\section{Discussion}

Fibrin sealant contributes to wound healing by producing local haemostasis and by stimulating the influx of macrophages which produce factors that cause angiogenesis, fibroblast proliferation and collagen production ${ }^{22-25}$. Additional sealing has been advocated for normal and high-risk colonic anastomoses in patients to prevent anastomotic leakage ${ }^{3-7}$. In the rat model, however, application of human and rat fibrinogen has a negative effect on the healing colonic anastomosis ${ }^{10}$. Since anastomoses are contaminated and fibrin is a culture medium for pathogens, antibiotics in the adhesive may prevent infection. Clindamycin and cefotaxime can be added to fibrin adhesive without impairing its clotting behaviour ${ }^{9}$.

Table 1

Adhesions of colonic anastomoses in the rat

\begin{tabular}{|c|c|c|c|c|c|c|c|c|c|c|c|c|c|}
\hline \multirow[b]{2}{*}{ Group } & \multirow[b]{2}{*}{$n$} & \multicolumn{4}{|c|}{ Day 2} & \multicolumn{4}{|c|}{ Day 4} & \multicolumn{4}{|c|}{ Day 7} \\
\hline & & 0 & $1+$ & $2+$ & $3+$ & 0 & $1+$ & $2+$ & $3+$ & 0 & $1+$ & $2+$ & $3+$ \\
\hline 1 (Control) & 30 & 0 & 6 & 4 & 0 & 0 & 9 & 1 & 0 & 0 & 6 & 4 & 0 \\
\hline 2 (Fibrin sealant) & 30 & 2 & 3 & 5 & 0 & 1 & 3 & 6 & $0^{*}$ & 0 & 6 & 4 & 0 \\
\hline 3 (Fibrin sealant and antibiotics) & 30 & 0 & 4 & 4 & 2 & 0 & 0 & 3 & $7^{*}$ & 0 & 2 & 5 & 3 \\
\hline
\end{tabular}

${ }^{*} P<0.05$ (group 1 versus groups 2 and $3, \chi^{2}$ test)

Table 2 Concentration and relative change of collagen in colonic anastomoses in the rat

\begin{tabular}{|c|c|c|c|c|}
\hline Site & Group & Day 2 & Day 4 & Day 7 \\
\hline Proximal to anastomosis & $\begin{array}{l}1 \\
2 \\
3\end{array}$ & $\begin{array}{ll}91(8) & (-49) \\
82(5) & (-50) \\
68(6) & (-48)\end{array}$ & $\begin{aligned} 109(7) & (-29)^{*} \\
85(9) & (-47) \\
81(4) & (-32)\end{aligned}$ & $\begin{array}{cl}158(11) & (-7)^{*} \\
102(4) & (-38) \\
92(5) & (-5)\end{array}$ \\
\hline Anastomosis & $\begin{array}{l}1 \\
2 \\
3\end{array}$ & $\begin{array}{ll}97(6) & (-44) \\
77(6) & (-52) \\
67(3) & (-48)\end{array}$ & $\begin{aligned} 113(6) & (-26)^{*} \\
81(9) & (-49) \\
80(4) & (-32)\end{aligned}$ & $\begin{array}{ll}152(7) & (-11) \\
139(3) & (-15)^{*} \\
106(6) & (+8)\end{array}$ \\
\hline Distal to anastomosis & $\begin{array}{l}1 \\
2 \\
3\end{array}$ & $\begin{array}{cc}135(10) & (-22) \\
131(6) & (-19) \\
98(6) & (-26)\end{array}$ & $\begin{array}{l}146(7)(-6)^{*} \\
130(5)(-19) \\
102(4)(-15)\end{array}$ & $\begin{array}{l}157(11)(-8)^{*} \\
144(3)(-11) \\
113(7)(+15)\end{array}$ \\
\hline
\end{tabular}

Values are mean(s.e.m.) expressed in micrograms per milligram dry weight; values in parentheses are the relative percentage changes compared with the individual control value. ${ }^{*} P<0.05$ (day 4; group 1 versus group 2; day 7: proximal, group 1 versus group 2; anastomosis, group 2 versus group 3; distal, group 1 versus group 3; ANOVA and Newman-Keuls test) 

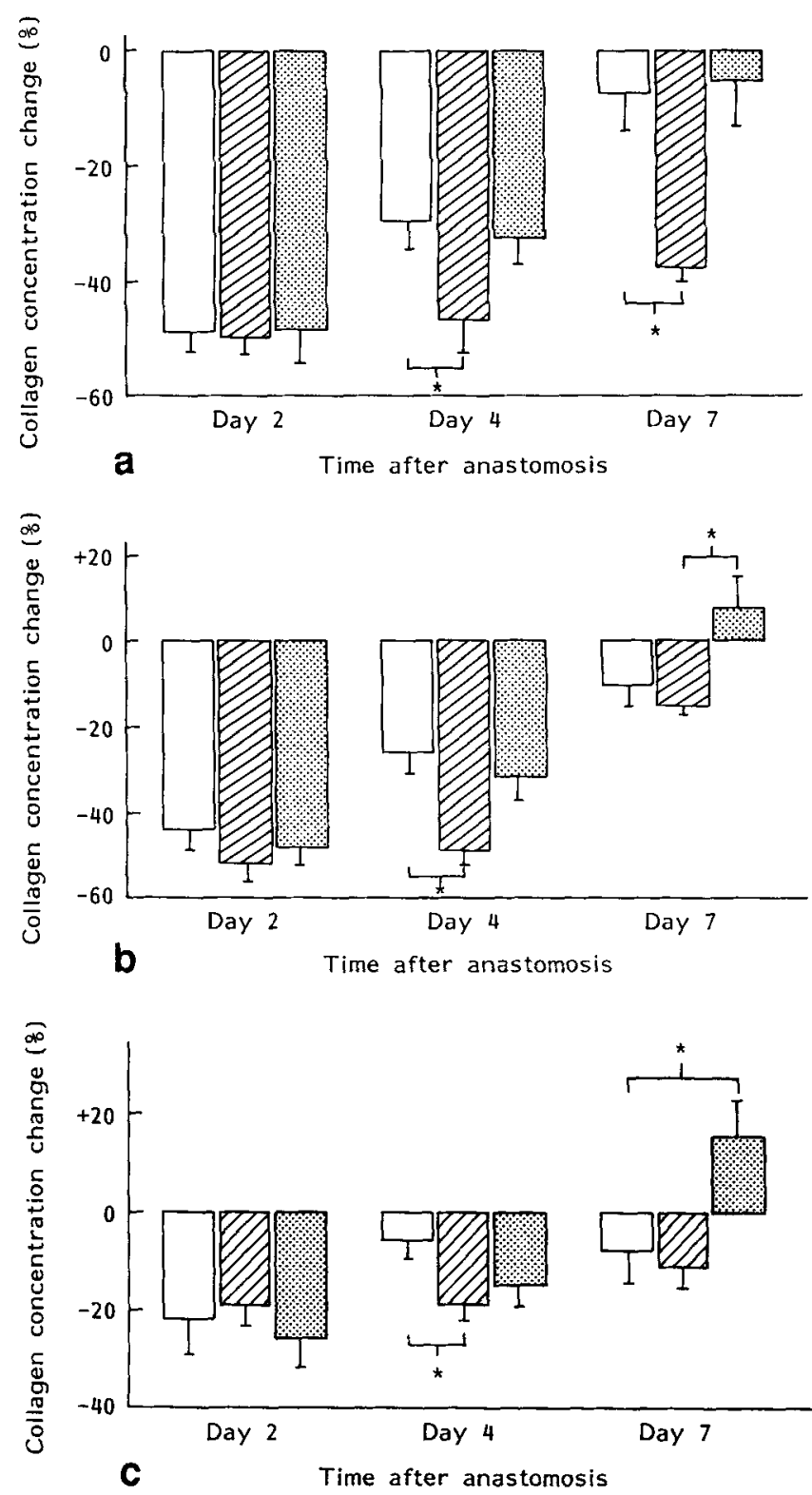

Figure 2 Relative changes in collagen concentrations a proximal to colonic anastomosis; $\mathbf{b}$ in colonic anastomotic area; $\mathbf{c}$ distal to colonic anastomosis. Values are mean( s.e.m.) percentage changes compared with

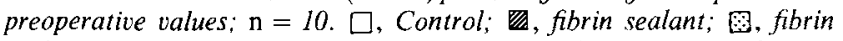
sealant plus antibiotics. ${ }^{*} \mathrm{P}<0.05$ ( $A N O V A$ and Newman-Keuls test)

The application of fibrin sealant resulted in increased adhesion formation around the anastomosis on day 4 . This was more prominent after addition of antibiotics. On day 7 this difference was not present. Others have found that fibrin glue prevents adhesion formation to peritoneal-muscular defects ${ }^{26}$ A possible explanation for the difference may be the presence of colonic bacteria in this model.

On day 2 the bursting pressure was significantly higher after sealing with antibiotic-fibrin complex. This did not correlate with diminished collagen degradation, and may be caused by mechanical bonding properties of the adhesive. Addition of antibiotics might inhibit degradation of the fibrin clot during the first few days and improve the adhesive property.

Application of fibrinogen produced a lower bursting pressure on day 4 , but this was prevented by addition of antibiotics to the fibrin sealant. In group 2 the lower bursting pressure on day 4 correlated with reduced collagen concentration. This decreased collagen concentration may account for the lower bursting pressure because bursting pressure is dependent mainly on submucosal collagen ${ }^{14}$.

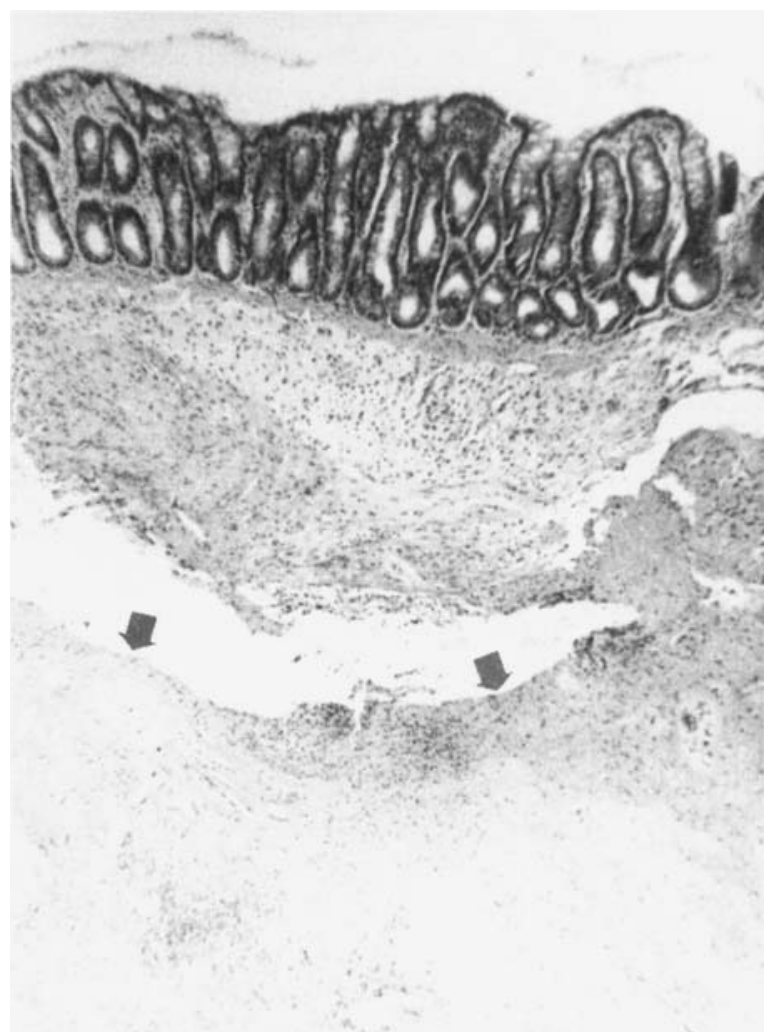

Figure 3 Histological section on day 4 after operation of a fibrinogen-sealed colonic anastomosis (arrows). The submucosa and fibrin sealant show cellular infiltrate. (Haematoxylin and eosin stain, original magnification $\times 80$ )

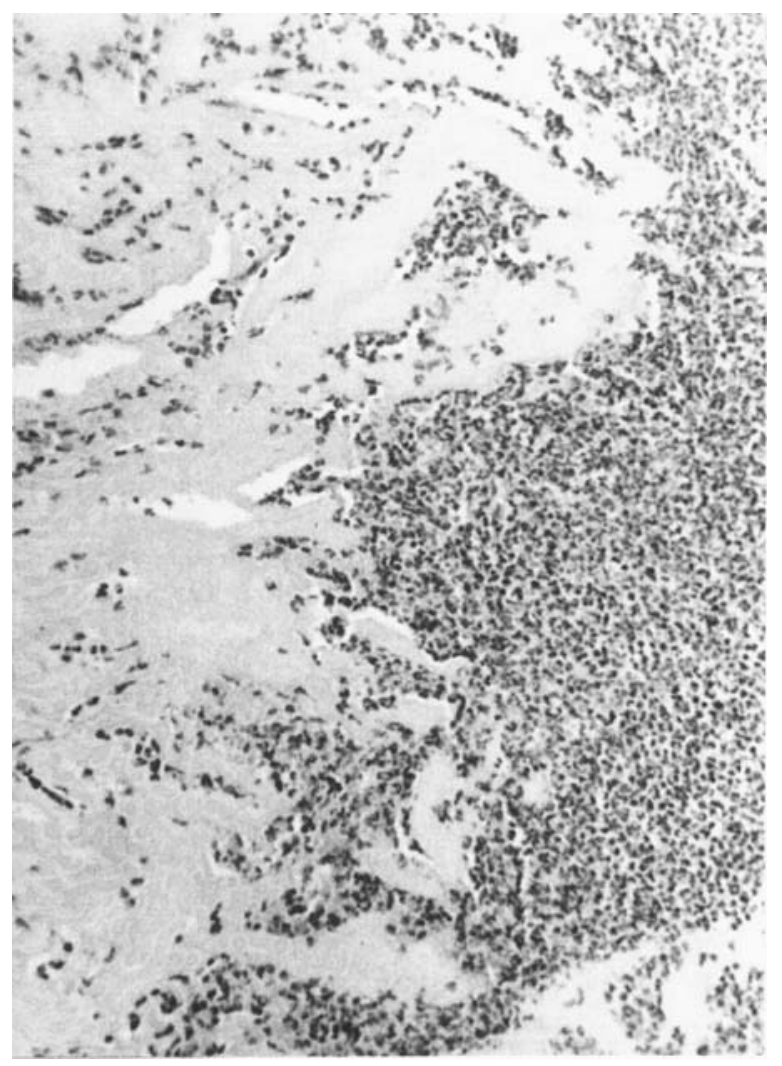

Figure 4 Detail of fibrin sealant showing massive cellular inflitrate of mainly neutrophilic granulocytes. (Haematoxylin and eosin siain, original magnification $\times 160$ ) 
Addition of antibiotics to the sealant gave almost the same hydroxyproline values on day 4 as in control animals. The reduced degradation of collagen after addition of antibiotics may be explained by reduced bacterial infection and inflammatory reaction. On day 4 the neutrophilic infiltration of the anastomoses with antibiotic-fibrinogen was significantly reduced.

On day 7 the net hydroxyproline change in the anastomotic segment as well as distal to it was positive and significantly higher in group 3. This did not result in a higher bursting pressure. At this time the intestine is weakest proximal to the anastomosis, as shown by the point of disruption. On day 7 , therefore, bursting pressure is not a good measure of anastomotic collagen concentration. The finding of asymmetrical collagen changes around the anastomosis has been reported in other studies ${ }^{14,27}$. This study demonstrated that collagen changes were more marked proximally and explains why the rupture occurred almost exclusively proximal to the anastomosis on testing the bursting pressure on day 7. No explanation for this pattern of collagen distribution can be found.

Histological examination showed excessive accumulation of neutrophilic granulocytes in the fibrin sealant covering the anastomosis on days 2 and 4 . Fibrinogen gives rise to infiltration of granulocytes and local fibrin deposition may predispose to local infection and inflammation. Under normal conditions, deposition of fibrin occurs within $3 \mathrm{~h}$ and the wound is infiltrated by granulocytes, followed by macrophages ${ }^{28}$ during the first $24 \mathrm{~h}$. Foreign material, e.g. fibrin, prolongs the inflammatory phase and provides a favourable site for bacterial proliferation. A significant reduction in the lowering of hydroxyproline concentration around the anastomosis was observed by Mastboom et al..$^{29}$ using germ-free rats. The results of the present study with antibiotics suggest that local bacterial infection contributes to collagen degradation following the construction of a colonic anastomosis.

Neutrophilic granulocytes and bacteria are sources of proteolytic enzymes including collagenase and may cause increased collagen breakdown in the intestinal wall. The postoperative decrease of breaking strength of colonic anastomoses is not apparent in rats with neutropenia ${ }^{30}$. In this model the increased number of neutrophils at the site of the anastomosis is responsible for the increased loss of hydroxyproline in the colonic wall following the addition of fibrin sealant. The results do not show enhanced healing of colonic anastomosis following sealing with fibrin glue, contrary to some other studies ${ }^{3-7}$. Addition of antibiotics to the fibrin sealant improved the mechanical properties of the anastomosis on day 2 and abolished the decrease in bursting pressure on day 4 . The addition of antibiotics may be useful in the clinical application of fibrin sealant.

\section{Acknowledgements}

The authors wish to thank Immuno AG, Vienna for financial and material support for this study. We are also grateful to Mrs L. M. H. Quist and Mr G. Visser for expert technical assistance.

\section{References}

1. Goligher JC, Graham NG, de Dombal FT. Anastomotic dehiscence after anterior resection of rectum and sigmoid. $\mathrm{Br} J$ Surg 1970; 57: 109-18.

2. Fielding JP, Stewart-Brown S, Blesovsky L, Kearny G. Anastomotic integrity after operations for large-bowel cancer: a multicentre study. Br Med J 1980; 281: 411-14.

3. Scheele J, Herzog J, Mühe E. Fibrin glue protection of digestive anastomoses. Zentrabl Chir 1978; 103: 1325-36.

4. Pointner $\mathbf{R}$, Villinger $\mathbf{R}$. Vorbeugung der intraperitonealen Nahtinsuffizienz durch Einsatz von Fibrin kleber. Zentralbl Chir $1984 ; 109 ; 1146-8$
5. Athanasiadis $\mathrm{S}, \mathrm{Kuhlgatz} \mathrm{Ch}$, Girona I. Additional fibrin glueing in surgery of colon and rectum. Zentralbl Chir 1984; 109: 1107-11.

6. Waclawiczek $\mathrm{HW}$, Boeck1 O. Clinical experience from fibrin sealing in general and thoracic surgery. Zentralb/ Chir 1986; 111 16-24.

7. Giardino R, Brulatti M, Franchini A. Colonic anastomoses protected with fibrin sealant. In: Schlag G, Redl H, eds. Fibrin Sealant in Operative Medicine. General Surgery and Abdominal Surgery. Vol. 6. Heidelberg: Springer-Verlag, 1986: 155-8.

8. Nordkild $\mathbf{P}$, Hjortrup A, Kjærgaard J. Tissue adhesives and intestinal anastomosis. Ann Chir Gynaecol 1986; 75: 205-8.

9. Houston KA, Rotstein OD. Fibrin sealant in high-risk anastomoses. Arch Surg 1988; 123: 230-4.

10. van der Ham AC, Kort WJ, Weijma IM, van den Ingh HFGM Jeekel $\mathbf{J}$. The effect of fibrin sealant on the healing colonic anastomosis in the rat. Br J Surg 1991; 78: 49-53.

11. Gottrup F. Healing of incisional wounds in stomach and duodenum: collagen distribution and relation to mechanical strength. Am J Surg 1981; 141: 222-7.

12. Wise L, McAlister W, Stein T, Schuck P. Studies on the healing of anastomoses of small and large intestines. Surg Gynecol Obstet $1975 ; 141: 190-4$.

13. Jiborn $\mathbf{H}$, Ahonen J, Zederfeldt B. Healing of experimental colonic anastomoses: III. Collagen metabolism in the colon after left colon resection. Am J Surg 1980; 139: 398-405.

14. Cronin K, Jackson DS, Dunphy JE. Changing bursting strength and collagen content of the healing colon. Surg Gynecol Obstet 1968; 126: 747-53.

15. Hawley PR, Hunt TK, Dunphy JE. Etiology of colonic anastomotic leaks. Proc $R$ Soc Med 1970; 63: 28-30.

16. Yamakawa $\mathrm{T}$, Patin $\mathrm{CS}$, Sobel $\mathrm{S}$ et al. Healing of colonic anastomoses following resection for experimental 'diverticulitis'. Arch Surg 1971; 103: 17.

17. Ohlsson K. Polymorphonuclear leukocyte collagenase. In: Woolley D, Evanson J, eds. Collagenase in Normal and Pathologic Connective Tissue. Chichester: Wiley, 1980: 209-22.

18. Peterkovsky B. Bacterial collagenase. Methods Enzymol 1982; 82: $453-71$.

19. Pointer R, Kofler H, Offer Ch, Schwab G. The kinetics of antibiotic release from a fibrin-clotting system: an animal experiment. In: Schlag G, Redl H, eds. Fibrin Sealant in Operative Medicine. General Surgery and Abdominal Surgery. Vol. 6 Heidelberg: Springer-Verlag, 1986: 194-8.

20. Stegemann H, Stalder K. Determination of hydroxyproline. Clin Chim Acta 1967; 18: 267-73.

21. Grant RA. Estimation of hydroxyproline by the AutoAnalyser J Clin Pathol 1964; 17: 685-6.

22. Banerjee SK, Glynn LE. Reactions to homologous and heterologous fibrin implants in experimental animals. Ann $N Y$ Acad Sci 1960; 86: 1054-7.

23. Leibovich SJ, Ross R. A macrophage-dependent factor that stimulates the proliferation of fibroblasts in vitro. Am J Pathol 1976; 84: $501-13$.

24. Pohl J, Bruhn HD, Christophers E. Thrombin and fibrin-induced growth of fibroblasts: role in wound repair and thrombus organization. Klin Wochenschr 1979; 57: 273-7.

25. Petrelli NJ, Cohen HC, DeRisi D et al. The application of tissue adhesives in small-bowel anastomoses. I Surg Oncol 1982; 19: $59-61$.

26. de Virgillio C, Dubrow T, Sheppard BB. Fibrin glue inhibits intra-abdominal adhesion formation. Arch Surg 1990; 125: $1378-82$.

27. Jiborn H, Ahonen J, Zederfeldt B. Healing of experimental colonic anastomosis: the effect of suture technique on collagen concentration in the colonic wall. Am J Surg 1978; 135: 333-40.

28. Hesp WLEM, Hendriks Th, Schillings PHM, Lubbers EJC, de Boer HHM. Histologic features of wound repair: a comparison between experimental ileal and colonic anastomoses. $\mathrm{Br} J$ Exp Pathol 1985; 66: 511-18.

29. Mastboom WJB, Hendriks T, de Boer HHM. Collagen changes around intestinal anastomoses in germ-free rats. Br J Surg 1989; 76: 797-801.

30. Högström $\mathbf{H}$, Haglund $U$. Neutropenia prevents decrease in strength of rat intestinal anastomosis: partial effect of oxygen free radical scavengers and allopurinol. Surgery 1986;99: 716-20.

Paper accepted 3 December 1991 